\title{
Retracted HIV Study Provides New Information about the Status of the in Vitro Inhibition of DNA Replication by Backbone Methylation
}

\author{
Henk M. Buck \\ Kasteel Twikkelerf 94, Tilburg, The Netherlands \\ Email: $\underline{\text { h.m.buck@ziggo.nl }}$ \\ Received 7 January 2015; accepted 23 January 2015; published 28 January 2015 \\ Copyright (C) 2015 by author and Scientific Research Publishing Inc. \\ This work is licensed under the Creative Commons Attribution International License (CC BY). \\ http://creativecommons.org/licenses/by/4.0/ \\ (c) (i) Open Access
}

\begin{abstract}
In this publication attention is given to a retracted article in Science at the end of 1990 concerning the HIV-1 inhibition by a modified backbone DNA as the phosphatemethylated DNA. A disproportion in the presented data resulted in a faulty generalization of the (bio)chemical characteristics of the phosphatemethylated DNA (18- and 20-nucleotides). In the confusion and the outside pressure a related study in Nucleic Acids Research on the in vitro dynamics of a regiospecific inhibition of DNA duplication with long (20- and 18-nucleotides) and short (8-nucleotides) phosphatemethylated DNA was completely ignored. A restoration will be given based on a comprehensive view demonstrating the unique molecular and conformational properties of phosphatemethylated DNA in their (bio)chemistry towards natural DNA and RNA (HIV-1 RNA loops).
\end{abstract}

\section{Keywords}

Phosphatemethylated DNA, Conformational Study, HIV-1, E. coli pab B Gene, in Vitro Inhibition of DNA Replication

\section{Introduction}

After the publication in Science entitled Inhibition of HIV-1 Infectivity by Phosphate-Methylated DNA: Retraction of Moody et al. [1] a number of articles have been published in order to reduce the imbalance between the various passages in the Retraction (presented as a Technical Comment) and the "meltdown" of the bio- and physical chemical properties of phosphatemethylated DNA [2]-[6]. The Retraction mainly focused on the small 
degree of methylation of the 20-nucleotide DNA's. These results conflict with their achievement in the in vitro regiospecific inhibition of DNA duplication with long and short fragments, prepared in a similar manner as in the HIV-study [7]. The suppression of the DNA polymerase I (Klenow fragment) in the inhibition experiments with the neutrally backbone-modified DNA's as inhibitors, has been explicitly demonstrated and may be considered as an additional support for the synthesis of the methylated DNA backbones [7].

\section{Methods and Materials}

After the HIV-publication in Science [8], HPLC analysis was carried out to determine the degree of backbonemethylation. The procedure for relatively long fragments was developed by Koole et al. [7] [9] and based on the following reaction sequence:

\section{natural DNA $\rightarrow$ base-protection $\rightarrow$ phosphate-methylation $\rightarrow$ base-deprotection}

The base-protection was carried out with the 9-fluorenylmethoxycarbonyl (Fmoc) group, the methylation with p-toluenesulphonyl chloride and methanol, and the base-deprotection with triethylamine. In the Retraction it was concluded that the protection of the bases resulted in an (almost) insoluble mixture leading to low yields in the following steps [1]. As a consequence of the individual organization around the Retraction, the attention was focused on the apparent failure of the phosphate methylation of the natural DNA.

In the proofs, the selectivity of the HIV-1 viral inhibition was maintained [10] but removed in the final text of the Retraction: "There is no evidence to suggest that the observed antiviral effects should be ascribed to the phosphate-methylation of natural DNA”.

The correctness of the synthetic part of the Technical Comment obtains a doubtful or negative assessment with the quote: "This result contrasts with earlier statements that the degree of phosphate-methylation of tested DNA was $90 \%$ to 100\%” (see Regiospecific inhibition of DNA duplication by antisense phosphate-methylated oligonucleotides of Moody et al. [7]). These experiments were carried out with long and short modified DNA's (18and 8-mers), prepared according to Koole's procedure.

Besides, the specific conformational aspects of phosphatemethylated DNA were left behind in the Retraction. It should be assigned that we are dealing with a high selectivity and enhanced duplex formation of phosphatemethylated DNA (a fixed B-conformation) for its complementary natural DNA (A- and B-conformation) which is in sharp contrast with the poor hybridization affinity at the RNA level (A-conformation). The established selectivity and pronounced duplex formation for natural DNA in contrast to RNA has been concluded from model studies for short phosphatemethylated DNA fragments with 2 - 5 nucleotides, vide infra [2]-[6].

Actually, the absence of a regioselective inhibition of four selected HIV-1 target regions TAR, PBS, NEF, and VIF in the Science-study, as confirmed in a subsequent report [10], is in excellent correspondence with these model studies. Additionally, negative results, i.e. the absence of inhibition were omitted in the Retraction.

In a private communication, Iyer confirms the absence of anti-HIV-1 activity with phosphatemethylated DNA's [5] [11]-[14].

\subsection{Inhibition of DNA Duplexation by Phosphatemethylated Oligodeoxynucleotides}

From the biological model proofs, i.e. the regiospecific inhibition of DNA duplication and the 1H NMR data, there is a distinct indication that the phosphate-backbone in the natural DNA was methylated [7].

The E. coli pab B gene, coding for para-aminobenzoate synthetase, inserted in the M13mp18 phage was used as template for a phosphatemethylated 18- and 8-mer (concentration $3 \mu \mathrm{M}$ ), complementary to a pair of selected template regions [15]. The relative synthesis activity along the template strand shows a sharp decrease precisely at the selected region(s) downstream of natural d(AGTAATCACAGCGGGAGA), complementary to the 14 - 31 region: -TCTCCCGCTGTGATTACT-, used as the primer for the sequencing reaction. The corresponding phosphatemethylated DNA was unable to act as a primer for Klenow DNA polymerase I. Thus, the Klenow fragment fails to recognize the modified DNA as primer. An arbitrary selected phosphatemethylated d(CTGCTAGAGATTTTCCACAC) has, as to be expected, no impact on the progress of the synthesis. The activity as measured for the 18- and 8-mer at room temperature and $0^{\circ} \mathrm{C}$ respectively, is given in Figure 1 . The 18-mer d(CACTCACCCATGAACAGC) is complementary to the nucleotide sequence for the -110 - -93 region: -GCTGTTCATGGGTGAGTG- and the 8-mer d(AGCCTGAC) is complementary to the 1455 - 1462 region: -GTCAGGCT-. In order to quantify the effect of the inhibition, the density of each band of the sequencing 

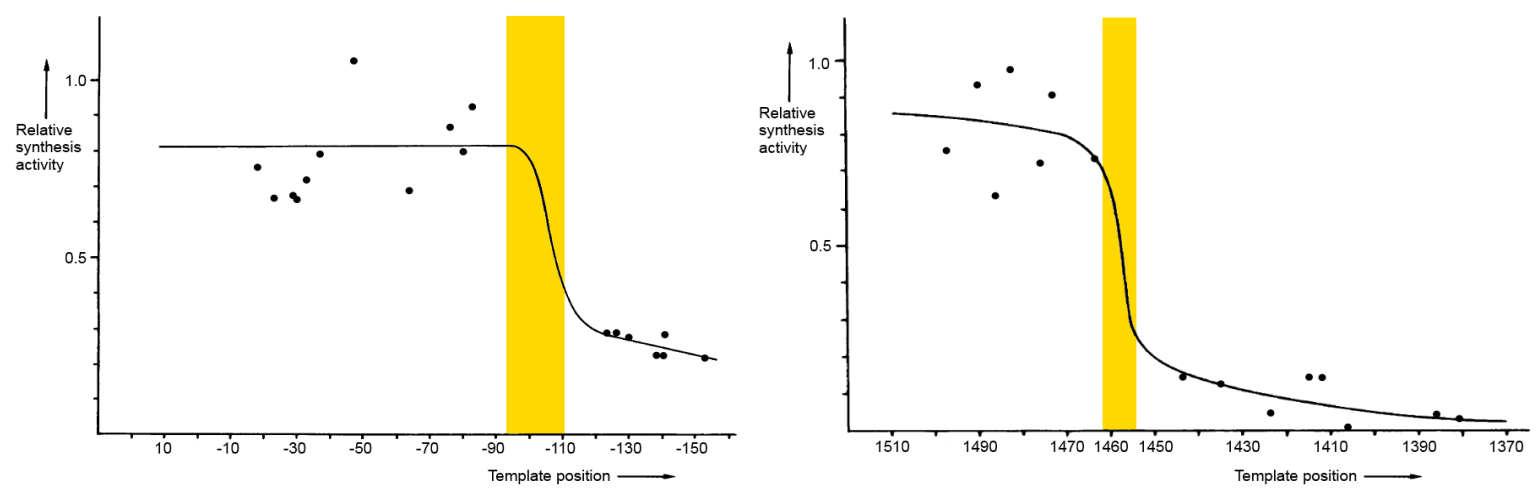

Figure 1. Relative synthesis activity along the template strand. The positions of the phosphatemethylated 18-mer d(CACTCACCCATGAACAGC) complementary to the -110 - -93 region at room temperature (left) and the 8-mer d(AGCCTGAC) complementary to the $1455-1462$ region at $0^{\circ} \mathrm{C}$ (right) are indicated with the yellow segment. The method for the determination of the relative synthesis activity along the template strand is given in the text.

pattern was measured optically. Eliminating the normally occurring density variation due to sequence-dependent strong and weak dideoxy stops, the ratio of the absorbance of the sequencing bands of this pattern with inhibitor and the corresponding bands of the reference pattern was used as a measure for the relative synthesis activity along the template strand. The stop of any synthesis activity after the inhibition region is the result of the absence of a natural primer. For the progress of the duplication after the inhibited regions, the phosphatemethylated DNA should be coupled with a natural fragment complementary with the nucleotide sequence of the template. This aspect that obtained not much attention in the anti-sense dynamics, may have its repercussions for other neutral backbone-modified DNA's as, e.g., methylphosphonates.

In that respect it is of interest to take notice of recent investigations of Song et al., based on structural/sequence motifs in interruption processes of duplication [16], and former conformational studies concerning the allosteric behaviour induced by phosphatemethylated DNA on its natural complementary strand [2]-[6].

These results based on a site-specific inhibition of the DNA replication process were omitted in the Retraction. Generally, the melting temperatures of the modified 6-, 8-, 12-, and 18-mers showed sharp transitions. Obviously, the 8-mer was too short to prevent the action of Klenow polymerase I at room temperature.

\subsection{H NMR Spectroscopy of Phosphatemethylated 18-Mer d(CACTCACCCATGAACAGC) Used in the Inhibition of DNA Duplexation}

The methylation of the phosphate backbone was confirmed with $1 \mathrm{H}$ NMR. The assignment was based on the position of the exclusivity of the $\mathrm{POCH}_{3}$ chemical shift value in combination with an estimate of the percentage of methylation. The 1H NMR spectrum of the 18-mer, used as the complementary site of the $-110--93$ part of the E. coli pab B gene, is given in Figure 2. The 31P NMR spectra for the phosphatemethylated DNA and the corresponding natural DNA are given in the text.

The 1H NMR $200 \mathrm{MHz}$ subspectrum, the crucial part of the spectrum for the assignment of the backbonemethylation, is composed of a diastereomeric mixture. Although the $\mathrm{POCH}_{3}$ signals are complex too, they are distinct from the other proton resonances. This is clearly demonstrated for a number of phosphatemethylated dimers as shown in Figure 3 with the $1 \mathrm{H}$ NMR $600 \mathrm{MHz}$ spectrum of the $S_{\mathrm{P}}$ phosphatemethylated dimer d(ApC) [9]. Initially, the dimers were obtained as a mixture of $R_{\mathrm{P}}$ and $S_{\mathrm{P}}$ isomers. For their separation reversed-phase HPLC was used. A number of these dimers were used in self-complementary studies. The most interesting ones are the self-complementary phosphatemethylated Z-d(CpG) and B-d(GpC) for both diastereoisomers [2]-[5]. The left- and right handed miniduplexes, respectively, were clearly demonstrated with circular dichroism and NMR spectroscopy. These studies were helpful for our molecular understanding of one of the fundamental aspects in the dynamics of gene expression caused by epigenetics. In these studies the methyl group plays a dominant role [5] [6].

The $\mathrm{POCH}_{3}$ doublet is explicitly indicated. These compounds were prepared via the step-wise phosphoramidite procedure with Fmoc-protected nucleotides with 2 - 5 nucleotides, vide supra. Based on a comparison of the 


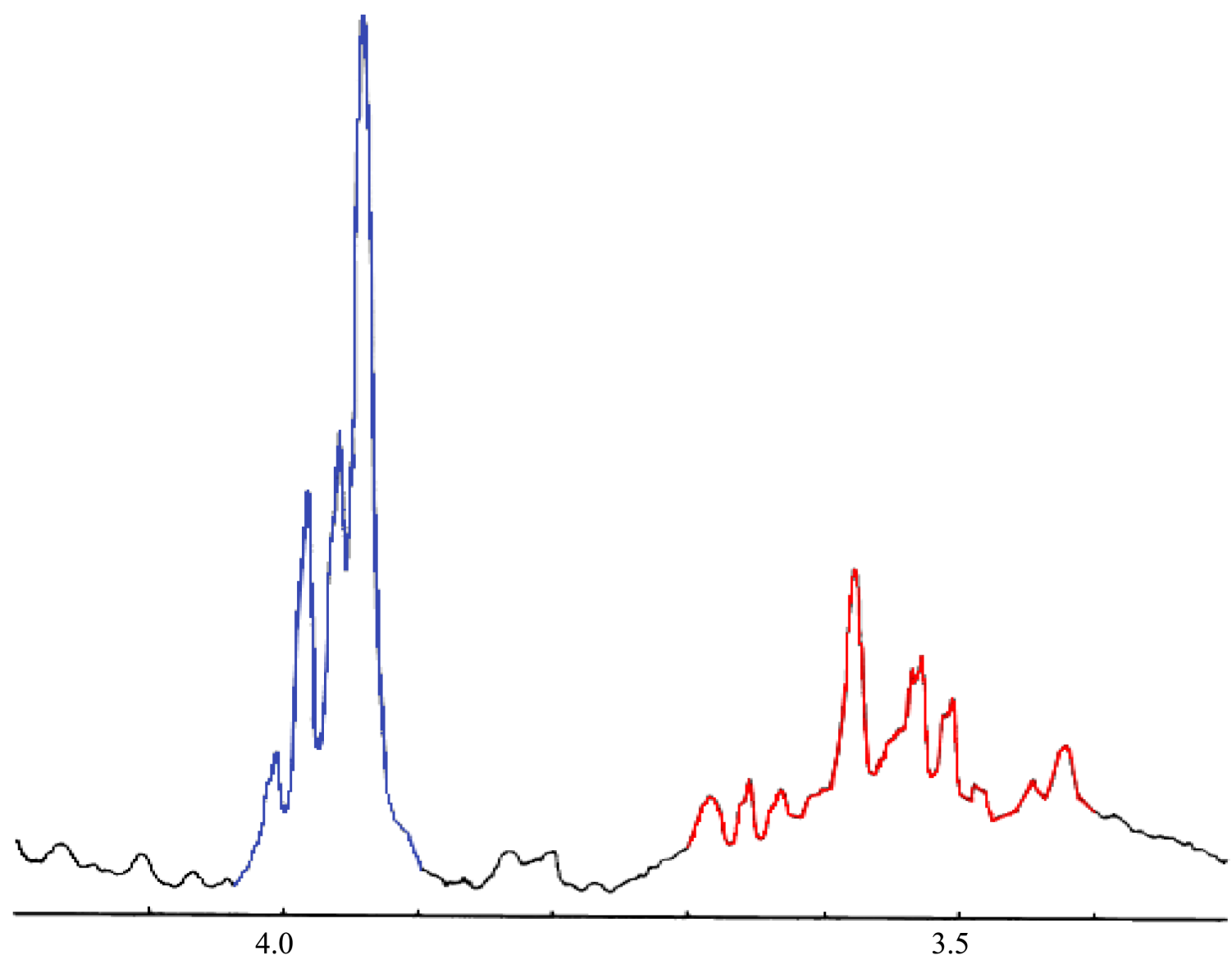

Figure 2. 1H NMR subspectrum of phosphatemethylated d(CACTCACCCATGAACAGC) for the POCH $\mathrm{H}^{-}$and 5'-end $\mathrm{H}_{5} / \mathrm{H}_{5 "}$ resonances (chemical shifts in $\mathrm{ppm}$ ) in the 3.7 - 3.4 region. These regions are indicated with blue and red, respectively.

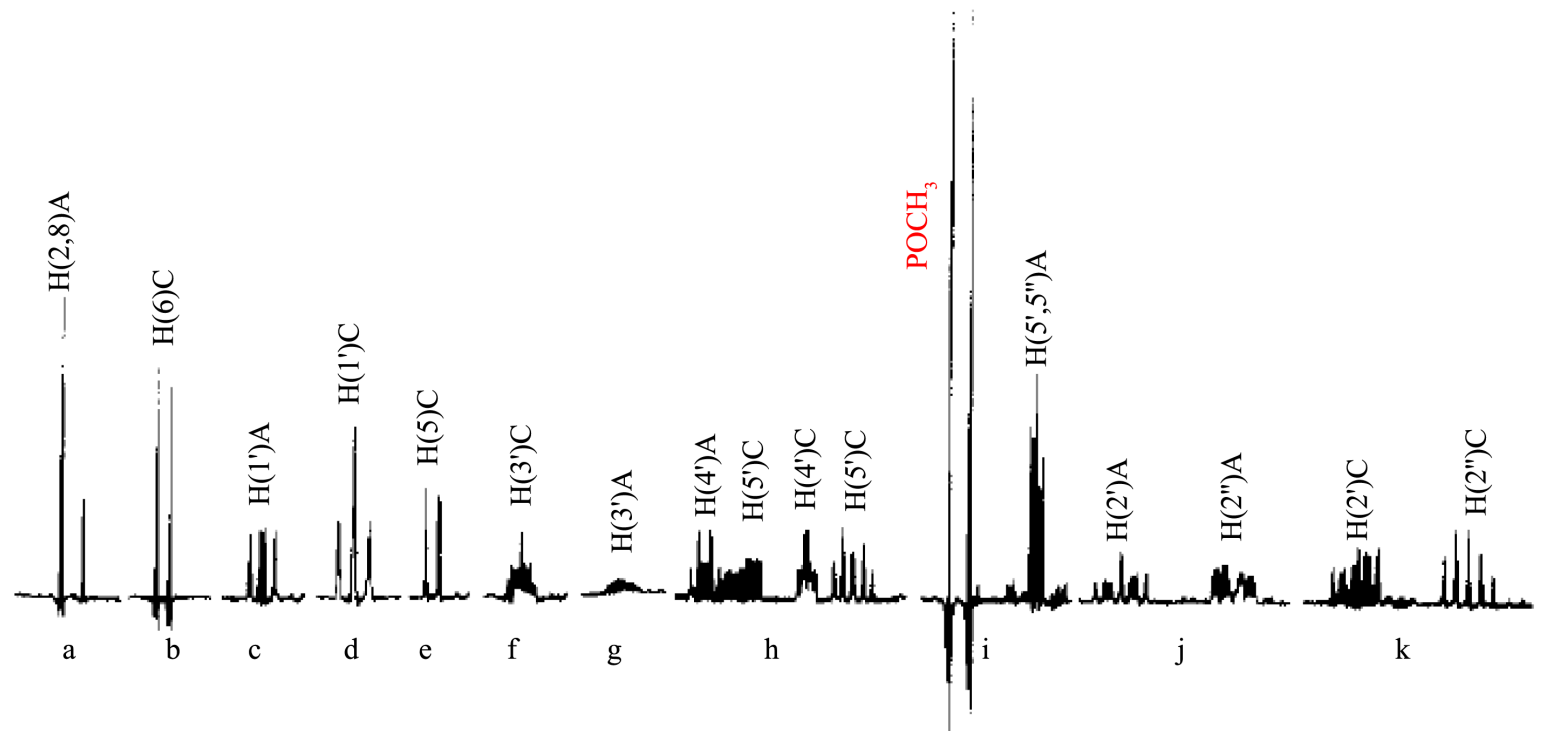

Figure 3. $600 \mathrm{MHz} 1 \mathrm{H}$ NMR spectrum of the $S_{\mathrm{p}}$ isomer of phosphatemethylated $\mathrm{d}\left(\mathrm{A}_{\mathrm{p}} \mathrm{C}\right)$. Regions (chemical shift in ppm): (a) 8.17 - 8.07; (b) 7.57 - 7.49; (c) 6.38 - 6.30; (d) 6.15 - 6.09; (e) 5.76 - 5.70; (f) 5.30 - 5.24; (g) 5.17 - 5.09; (h) 4.46 - 4.24; (i) 3.84 - 3.70; (j) 2.90 - 2.64; (k) 2.38 - 2.16. 
surface area of the $\mathrm{POCH}_{3}$ and 5'- end $\mathrm{H}^{\prime} / \mathrm{H} 5$ " resonances in the 3.7 - 3.4 ppm region with other proton resonances e.g., the combined H1' and cytosine H5 signals, an overall methylation of the backbone of at least $90 \%$ was abstracted. For the deprotection of the Fmoc-protected amino bases three hours were included. Model experiments demonstrated approximately 5\% demethylation [17]. The 31P NMR data of the phosphatemethylated DNA 18-mer at $2.0 \mathrm{ppm}$ showed one single broad resonance spectrum, due to the complexity of the diastereomeric mixture. In the corresponding natural DNA there is no significant chemical shift compared with the methylated one. In the absence of chiral phosphates separate peaks are identifiable.

\section{General Remarks Concerning the Duplication Study}

The general procedure concerning the DNA phosphate-backbone methylation, vide supra, was started via a DNA synthesizer for the preparation of natural DNA's with the following sequences d(CGAATC), d(AGCCTGAC), d(GGAATCCTGCAG), and d(CACTCACCCATGAACAGC). The latter one was used to describe the follow-up of the synthesis. The temporary protection of the bases with the Fmoc group and the methylation of the phosphate groups were accomplished in solution etc. This is in disagreement with the text of the Retraction: "It was concluded that the protection of the bases resulted in an (almost) insoluble mixture leading to low yields in the following steps".

The melting temperatures of the modified 6-, 8-, 12-, and 18-mers showed sharp transitions varying from $27^{\circ} \mathrm{C}$ to $75^{\circ} \mathrm{C}$. For the complete preparation and purification see Refs. [7] and [9].

After the publication of the Retraction, an explanation for the inhibition of the DNA replication of selected regions at the E. coli pab $B$ gene was suggested by the presence of triethyl ammonium- and possibly triethylmethyl ammonium cations (methyl transfer via the methylating agent) as by-products of the synthesis, vide supra [3]. The latter duplex is faclitated by electrostatic interaction between the positively charged triethylmethyl ammonium groups and the negatively charged phosphate groups in combination with the amphipathic character of the former group [3] [5] [19]. Through hydrogen bridging and (partial) methyl shielding of the phosphates, the duplex formation should be increased. For the success of the in vitro experiments covalent shielding, i.e., formation of a $\mathrm{POCH}_{3}$ bonding, is a prerequisite. The various DNA models are given in Figure 4.

\section{Conclusion}

Taking into account the contradictions in the experimental data and their corresponding interpretations, a disqualification of the scientific research with phosphatemethylated DNA and its corresponding abrupt ending [1] [8] [10] [18] cannot be regarded as credible or trustworthy.
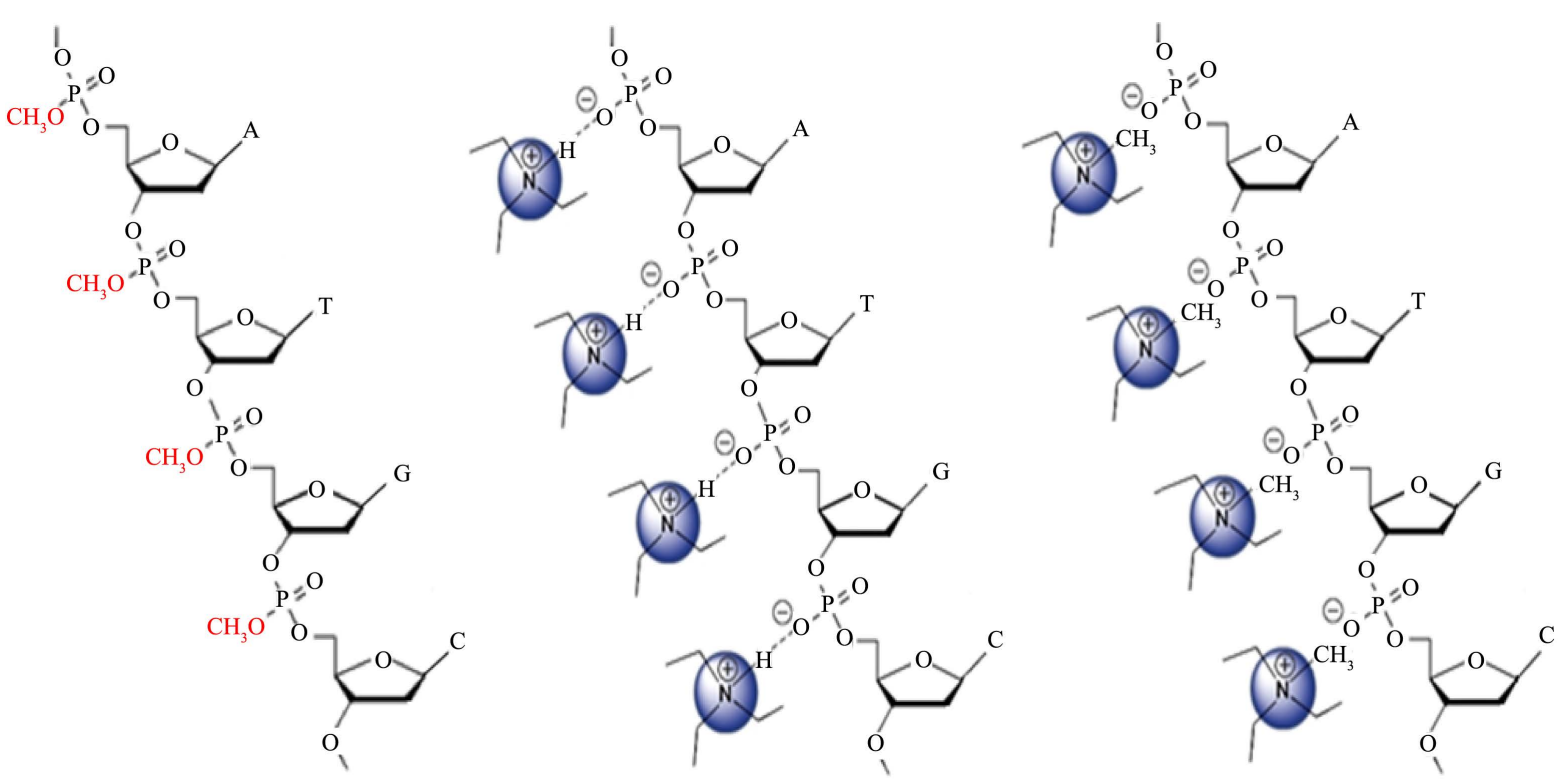

Figure 4. Backbone-modified DNA models. Covalent shielding with $\mathrm{PO}-\mathrm{CH}_{3}$ as methylphosphotriester (left), hydrogenbridging with triethyl ammonium cation (center) and cationic shielding with triethylmethyl ammonium ion (right). 


\section{References}

[1] Moody, H.M., Quaedflieg, P.J.L.M., Koole, L.H., van Genderen, M.H.P., Buck, H.M., Smit, L., Jurriaans, S., Geelen, J.L.M.C. and Goudsmit, J. (1990) Inhibition of HIV-1 Infectivity by Phosphate-Methylated DNA: Retraction. Science, 250, 125-126. http://dx.doi.org/10.1126/science.2218505

[2] Buck, H.M. (1999) A New Strategy for DNA Inhibition with Backbone Substituted DNA Analogues. Nucleosides Nucleotides Nucleic Acids, 18, 1397-1398. http://dx.doi.org/10.1080/07328319908044729

[3] Buck, H.M. (2004) The Chemical and Biochemical Properties of Methylphosphotriester DNA. Nucleosides Nucleotides Nucleic Acids, 23, 1833-1847. http://dx.doi.org/10.1081/NCN-200040620

[4] Buck, H.M. (2007) The Chemical and Biochemical Properties of Methylphophotriester DNA and RNA in Comparison with Their Corresponding Methylphosphonates: A Dynamical Model Description. Nucleosides Nucleotides Nucleic Acids, 26, 205-222. http://dx.doi.org/10.1080/15257770601112812

[5] Buck, H.M. (2011) DNA Systems for B-Z Transitions and Their Significance as Epigenetic Model: The Fundamental Role of the Methyl Group. Nucleosides Nucleotides Nucleic Acids, 30, 918-944. http://dx.doi.org/10.1080/15257770.2011.620580

[6] Buck, H.M. (2013) A Conformational B-Z DNA Study Monitored with Phosphatemethylated DNA as a Model for Epigenetic Dynamics Focused on 5-(Hydroxyl)Methylcytosine. Journal of Biophysical Chemistry, 4, 37-46. http://dx.doi.org/10.4236/jbpc.2013.42005

[7] Moody, H.M., van Genderen, M.H.P., Koole, L.H., Kocken, H.J.M., Meijer, E.M. and Buck, H.M. (1989) Regiospecific Inhibition of DNA Duplication by Antisense Phosphate-Methylated Oligodeoxynucleotides. Nucleic Acids Research, 17, 4769-4782. http://dx.doi.org/10.1093/nar/17.12.4769

[8] Buck, H.M., Koole, L.H., van Genderen, M.H.P., Smit, L., Geelen, J.L.M.C. and Goudsmit, J. (1990) Phosphate-Methylated DNA Aimed at HIV-1 RNA Loops and Integrated DNA Inhibits Viral Infectivity. Science, 248, 208-212. http://dx.doi.org/10.1126/science.2326635

[9] Koole, L.H., Moody, H.M., Broeders, N.L.H.L., Quaedflieg, P.J.L.M., Kuijpers, W.H.A., van Genderen, M.H.P., Coenen, A.J.J.M., van der Wal, S. and Buck, H.M. (1989) Synthesis of Phosphate-Methylated DNA Fragments Using 9-Fluorenylmethoxy-Carbonyl as Transient Base Protecting Group. Journal of Organic Chemistry, 54, 1657-1664. http://dx.doi.org/10.1021/jo00268a030

[10] Eijgenraam, F. (1991) Dutch Aids Researchers Feel Heat of Publicity. Science, 251, 1422-1423. http://dx.doi.org/10.1126/science.2006416

[11] Iyer, R.P. (2012) Private Communication.

[12] Iyer, R.P., Yu, D., Ho, N.-H., Devlin, T. and Agrawal, S. (1995) Methyl Phosphotriester Oligonucleotides: Facile Synthesis Using $N$-Pent-4-Enoyl Nucleoside Phosphoramidites. Journal of Organic Chemistry, 60, 8132-8133. http://dx.doi.org/10.1021/jo00130a008

[13] Iyer, R.P. (1999) Process for Making Oligonucleotides Containing O- and S-Methylphosphotriester Internucleoside Linkages. US Patent No. 5955599.

[14] Iyer, R.P. (2010) Nucleic Acid-Based Compounds and Methods of Use Thereof. US Patent No. 7709449.

[15] Kocken, H.J.M. (1989) Escherichia coli Para-Aminobenzoate Synthase Component I. Cloning, Sequence and in Vitro Mutagenesis of pabB. Ph.D. Thesis, University of Technology, Eindhoven.

[16] Song, W., Dominska, M., Greenwell, P.W. and Petes, T.D. (2014) Genome-Wide High Resolution Mapping of Chromosome Fragile Sites in Saccharomyces cerevisiae. Proceedings of the National Academy Science USA, 111, E2210E2218. http://dx.doi.org/10.1073/pnas.1406847111

[17] Kuijpers, W.H.A., Huskens, J., Koole, L.H. and van Boeckel, C.A.A. (1990) Synthesis of Well-Defined PhosphateMethylated DNA Fragments: The Application of Potassium Carbonate in Methanol as Deprotecting Reagent. Nucleic Acids Research, 18, 5197-5205. http://dx.doi.org/10.1093/nar/18.17.5197

[18] Maddox, J. (1990) Dutch Cure for Aids Is Discredited. Nature, 347, 411. http://dx.doi.org/10.1038/347411a0

[19] Ma, C.D., Wang, C., Acevedo-Vélez, C., Gellman, S.H. and Abbott, N.L. (2015) Modulation of Hydrophobic Interactions by Proximally Immobilized Ions. Nature, 517, 347-350. http://dx.doi.org/10.1038/nature14018 
Scientific Research Publishing (SCIRP) is one of the largest Open Access journal publishers. It is currently publishing more than 200 open access, online, peer-reviewed journals covering a wide range of academic disciplines. SCIRP serves the worldwide academic communities and contributes to the progress and application of science with its publication.

Other selected journals from SCIRP are listed as below. Submit your manuscript to us via either submit@scirp.org or Online Submission Portal.
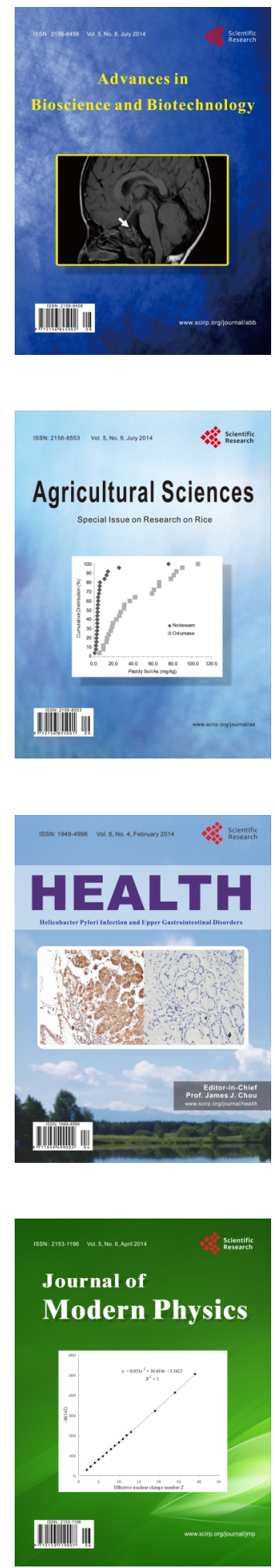
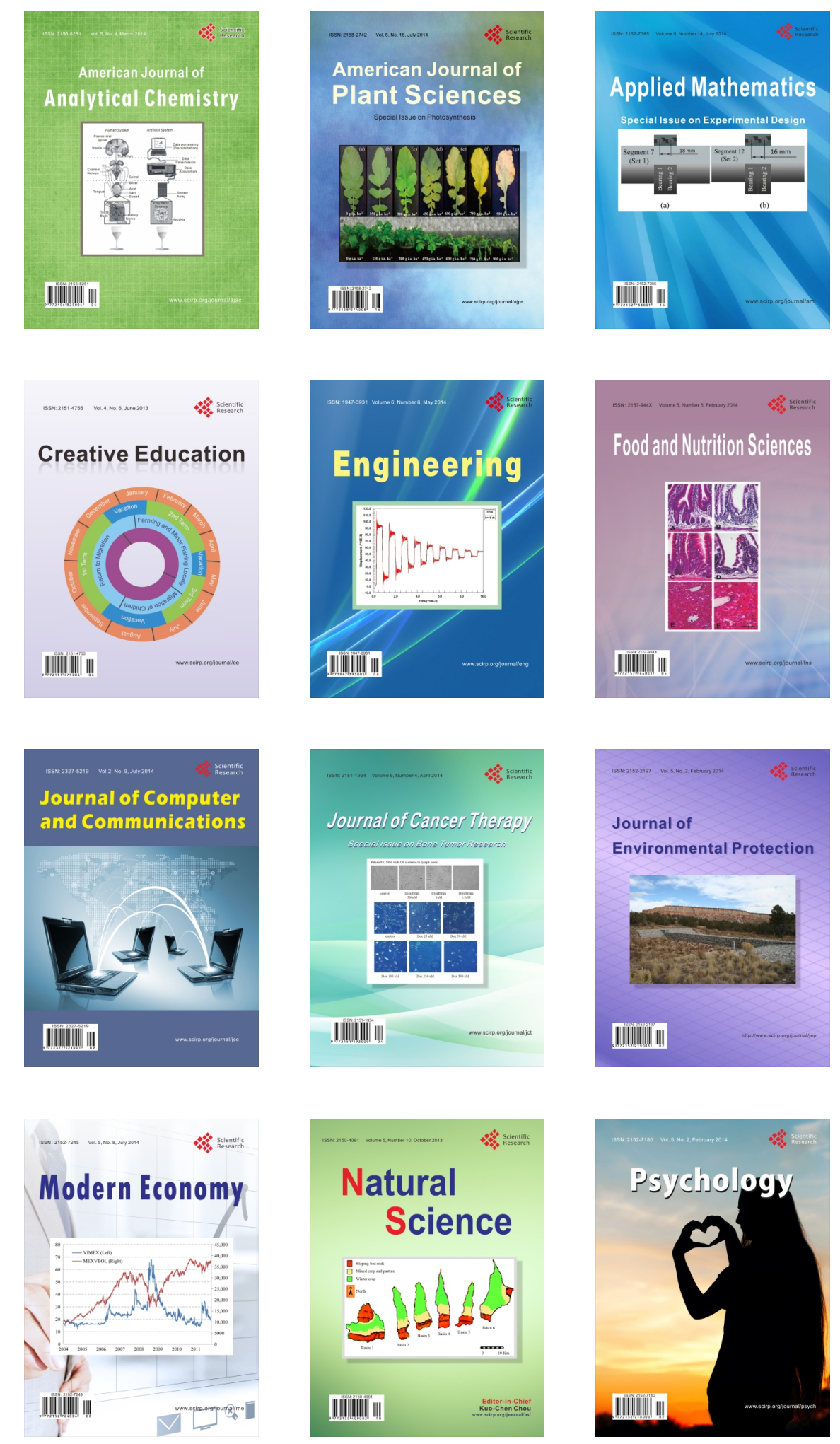